\title{
An Investigation of Oral Corrective Feedback in an ESL Listening and Speaking Class*
}

\author{
Ning Fan \\ School of Foreign Language, Zunyi Medical College, Zunyi, China
}

\begin{abstract}
The ability of listening and speaking has been playing an essential role in helping English as a Second Language (ESL) students in terms of academic performance and mental well-being. Oral corrective feedback (CF) provided by ESL teachers is important in the improvement of students' listening and speaking ability. However, conflicting results exist about the frequency of oral CF used by ESL teachers. The present paper focuses on the frequency of oral CF used by a teacher in a university ESL listening and speaking class. The results show that there are 13 types of oral CF in a total of 154 turns of interactions between the teacher and the students.
\end{abstract}

Index Terms — oral corrective feedback, frequency, English as a second language listening and speaking class

\section{INTRODUCTION}

\section{A. Statement of the Problem}

Instructors of English as a Second Language (ESL) Listening and Speaking classes usually use various types of oral corrective feedback (CF) to improve students' oral proficiency (Lyster \& Ranta, 1997). However, the frequency of using these oral CF strategies in language classes is often inconsistent across the different instructional settings. Lyster, Saito and Sato (2013) reviewed 12 descriptive studies of classroom CF and found that there was no agreement among the research as to what types of oral $\mathrm{CF}$ were used more frequently than the others. For example, the percent of using recasts was as high as 83\% in Sheen's (2004) study on adult learners of English as a Foreign Language (EFL) in Korea, while the percent of using recasts was only 31\% in Yang's (2009) study on learners of high school EFL in China. Therefore, further research into oral CF strategies in different instructional settings is still needed because of this contradictory evidence.

\section{B. Background Information}

Speaking proficiency plays an important role for students who are planning to study abroad. As the world becomes more and more interconnected, students tend to choose to study abroad after they complete high school or undergraduate study in their native countries. However, studying and living in a foreign country is never an easy thing to do. Students are likely to encounter numerous unexpected difficulties, among which using their second language to communicate with people around them may be the most difficult. If this communication problem cannot be addressed properly, it might be harmful for the students themselves psychologically and academically.

In terms of mental well-being, the students might experience psychological stress or feel isolated from their new surroundings if they cannot understand others or make themselves understood by speaking accurately and fluently. More importantly, their academic performance can be affected unfavorably if the interactions between the students and their professors are disrupted frequently because of the students' poor speaking and listening ability. Therefore, the proper emphasis on speaking and listening in a second language for those who intend to live or study in a foreign country is of great importance.

\section{Significance of the Study}

ESL Listening and Speaking classes can provide the students with a useful way of improving their communicative ability to use a target language ( $\mathrm{Li}, 2010)$. In order to make the students' speaking ability improve in a relatively short period of time, the instructors usually utilize various types of teaching methods to make classroom activities more effective. Among them, oral CF is an important method. Sarandi (2016) pointed out that "corrective feedback is an indication that all or part of language that learners produce is deviant" (p. 236). In an ESL Listening and Speaking class, the instructors can use a variety of oral CF strategies to encourage the students to notice gaps between their utterances and the target language. This may improve their speaking ability through the uptake of the oral CF and also repair their interlanguage, i.e., a version of a language produced by a foreign language learner. Sarandi (2016) further argued that "the widely accepted CF strategies are: $\underline{\text { a) }}$ recasts, $\underline{\mathrm{b}}$ ) metalinguistic explanation, $\underline{\mathrm{c})}$ elicitation, $\underline{\mathrm{d})}$ repetition, e) clarification requests, and f) explicit correction" (p. 236). These strategies are frequently used in the research that investigates the frequency of various oral CF strategies used in different instructional settings.

\footnotetext{
* Fund information: This paper was funded by Education Department of Guizhou Province, China (Project number: CJ-2016-2).
} 
Moreover, based on the differential oral proficiency levels of students, using appropriate oral CF strategies in a Listening and Speaking class can provide all students with suitable CF they need to improve their own speaking ability. For example, in a Listening and Speaking class, the instructors can use more output-pushing strategies for the more proficient students, while using more input-providing strategies to the less proficient students. Specifically, the output-pushing strategies are used because of the sociocultural framework that argues that the instructors should use the concept of scaffolding and "Zone of Proximal Development (ZPD)" to push these students to achieve desirable learning results (Aljaafreh \& Lantolf 1994). Meanwhile, input-providing strategies should be used because it is hard for the less proficient students to benefit from the scaffolding offered by the instructors. Whatever strategies instructors use, they are creating a language environment in their classrooms to immerse their students in the foreign language.

In addition, an investigation into the classification and frequency of oral CF in an university-level ESL class can also help those who teach at the same level make more informative decisions when providing oral CF. As will be presented in the following section, the existing literature about the frequency of providing oral $\mathrm{CF}$ often produce inconsistent findings. In this case, sometimes it would be difficult for the instructors to distinguish the more frequently utilized oral $\mathrm{CF}$ from the less frequently utilized ones. In addition, most existing studies utilized the classification of oral $\mathrm{CF}$ originated from Lyster and Ranta's 1997 study, which might be too narrow to cover the dynamic classroom environments.

\section{LITERATURE REVIEW}

The use of oral CF plays an essential role in facilitating students' oral performance in ESL Listening and Speaking classes (Sheen, 2004). In classroom interactions, the instructors tend to vary the frequency of providing different types of oral CF to the students since they teach in different instructional settings and face the students with different oral proficiency levels. Thus, research on the teaching practices using oral CF in classes usually leads to conflicting results. In this part, I will show how the studies of Sheen (2004), Panova and Lyster (2002) and Ellis, Basturkmen and Loewen (2001) on the use of oral CF produced conflicting results. Then I will briefly review oral CF studies with different levels of students to show that oral CF research of adult ESL learners is still needed.

\section{A. The Frequency of Feedback Types across Instructional Settings}

Sheen (2004) investigated the difference in instructors' use of oral CF types and the rate of learner uptake and repair across four different instructional settings, which are French Immersion, Canadian ESL, New Zealand ESL and Korean EFL. The author uses Lyster and Ranta's taxonomies of CF types of explicit correction, recasts, clarification requests, metalinguistic feedback, elicitation, repetition, or combinations (Lyster \& Ranta, 1997) to explore the research questions. In terms of the rate of learner uptake and repair, the author uses Lyster and Ranta's categorization of 'repair' and 'needs repair' (Lyster \& Ranta, 1997). There are four data sets from four different instructional settings in this study. Three of the four data sets are from existing studies, while one of them is from the author. The three existing data sets are from Lyster and Ranta (1997), Panova and Lyster (2002), and Ellis et al. (2001). The data from the author are from two communicative EFL classrooms, each of which has four to six adult Korean learners. Also, in order to collect the data from the author, two teachers record thirteen English lessons totaling 12 hours over a four-week period. The results show that among the four instructional settings, recast is used most frequently in Korean EFL (83\%), followed by New Zealand ESL (68\%), and French Immersion (55\%) and Canadian ESL (55\%). Specifically, in the data from the author, which is about the adult EFL in Korea, the frequency of other feedback types in addition to recast is also distinguished from the other three data sets. For example, the frequency of explicit correction is $11 \%$ to EFL in Korea, while it is $2.2 \%$ to Canadian ESL. The frequency of clarification requests is 3\% to EFL in Korea, while it is $11 \%$ to Canadian ESL. Various instructional settings can lead to different frequency of feedback types.

\section{B. The Frequency of Feedback Types to ESL Learners}

In addition to the fact that different instructional settings can provide inconsistent frequency of feedback types, the similar instructional settings can also produce these inconsistent findings. Ellis et al.'s (2001), and Panova and Lyster's (2002) study, both targeting ESL learners, will be reviewed to show the inconsistent findings on frequency of various types of feedback.

Ellis et al.'s (2001) study investigates the nature and extent of focus on form in communicative ESL lessons. The authors target two ESL classes in New Zealand, each of which has 12 students. 12 hours of classroom activities were audio-recorded in a length of two and a half weeks. The results show that recast is still the most frequently used feedback type (68\%), followed by explicit correction (12.7\%), elicitation $(6.9 \%)$, repetition $(5.8 \%)$, and clarification requests $(4.2 \%)$.

In contrast, Panova and Lyster's (2002) study presents different results as for the frequency of types of feedback. With the research question about feedback types that lead to the greatest amount of uptake, the authors first identify the different types of feedback used in the classroom. A class of 25 students in a Canadian ESL classroom was observed over a period of four weeks, with 18 hours of classroom interactions audio-recorded. Among the 412 feedback moves based on their observation, recast is used most frequently (55\%), clarification request (10.7\%), explicit correction $(2.2 \%)$, elicitation (3.6\%), repetition (1.5\%), which were all distinguished from those in Ellis et al.'s (2001) study. Thus, 
similar instructional settings, such as ESL, can also produce inconsistent findings on the frequency of oral CF types.

\section{Younger ESL Learners}

In addition to the conflicting results about the frequency of different types of oral CF, there are also studies that focus on young ESL students instead of adults. For example, using French-speaking children of grades five and six in intensive ESL programs as subjects, White (1991) investigated the effectiveness of teaching adverb placement to these children. The children were divided into two groups, with one group instructed on adverb placement and another on question formation. The results showed that only the group that was instructed on adverb placement knew that adverbs should not interrupt the verb and object. In Lyster and Ranta's (1997) research, their subjects were primary level students in Grade four, five, and six. The researchers collected data through classroom interaction, transcribed the data, and analyzed them using a model built for the study to disclose various moves in a sequence of error treatment. The results indicated that the teachers used recasts much more frequently than other feedback types, while recasts were ineffective in eliciting the students' self-repair. Also, Tsang's (2004) study involved secondary level students ranging from grade seven to 11 in Hong Kong. The study investigated the frequency of teacher feedback and the effectiveness of student uptake. The results showed that the most frequently used feedback types by the teachers were recast and explicit correction, and the students could produce the most self-repair when the feedback was provided as the form of repetition.

Therefore, as the literature about targeted subjects suggests there is still a need to investigate the frequency of oral $\mathrm{CF}$ in adult ESL settings. As Panove and Lyster (2002) pointed out that there are different factors that exist in terms of context, language, and cognition between adults and young learners (as cited in Lee, 2013).

The purpose of this study was to investigate the frequency of oral CF used by the instructor of an university-level ESL Listening and Speaking class. In the literature of oral CF research, similar or different instructional settings produced conflicting results of the oral CF frequency used by instructors. These results cause instructors themselves feel perplexed as to which types of oral $\mathrm{CF}$ are used more frequently and more effectively than others across these instructional settings. Thus, this study has attempted to address the problem of oral CF frequency, and add to the existing literature by focusing on an adult ESL Listening and Speaking class in an American university.

\section{THEORETICAL FRAMEWORK}

Two theories will be addressed in this part because they are closely connected to the analyses of oral CF and are frequently adopted as theoretical framework in the research of oral CF. The first theory is the interaction-hypothesis developed by Long in 1983 and 1996. Long (1983) argued that there were two stages involved in our interactions. The first stage was the negotiation of meaning occurring when the interlocutors were working together to make interactions move forward smoothly by resolving communication problems (Pawlak, 2014). The second stage was interactional modification through which the communication problems were resolved with the use of various types of strategies, such as repetitions or asking for clarifications (Pawlak, 2014). However, as Pawlak (2014) pointed out, this version of the interaction-hypothesis should be revised because it failed to elaborate on the relationship among negotiation, comprehension, and acquisition. In other words, it assumed that negotiation can lead to acquisition only because negotiation can facilitate comprehension which is the premise of acquisition. However, Long (1983) did not elaborate on these potential causal-effect relationships.

Long's (1996) revised version of interaction-hypothesis was more suitable for the analyses of oral CF. Long (1996) focused more on the process of negotiation of form which involved various types of conversational strategies used to provide corrective feedback such as explicit correction, elicitation, and repetition. The negotiation of form was important in the development of second language learning because it was useful to the improvement of some language learning areas, such as speaking and listening (Long, 1996). In terms of oral CF, Lyster et al. (2013) argued that recasts, one of the most frequently used type of oral CF, were closely connected with the use of interaction-hypothesis, and were helpful in improving students' communication performance because “[...] recasts are hypothesized to provide learners with a primary source of negative evidence while freeing up cognitive resources that would otherwise be used for semantic processing" (p. 10). In other words, oral CF, such as recasts, can help to improve learners' communication performance by correcting their oral errors in an efficient way and letting them have more time and energy to process other language related problems.

Another theory associated with oral CF was the skill acquisition theory, which is "best presented in L2 acquisition by the work of DeKeyser" (Polio, 2013, p.381). According to Polio (2013), there were three stages of development concerning skill acquisition theory: declarative, procedural, and automatic stages. Generally, students' errors in oral utterance were spotted and corrected by their teachers using either implicit or explicit types of strategies. In this case, if the teachers used prompts as an implicit way to correct the students' errors instead of providing corrections explicitly, the students were provided with "[...] scaffold opportunities for guided practice in the context of communicative interaction" (Lyster et al., 2013, p.11). This guided practice was helpful in improving the students' oral performance because it provided the students with opportunities to practice their thinking ability and to have access to correct declarative knowledge. Subsequently, in the stage of procedural development, it was more secured that the knowledge entering into this stage was correct, and should be proceduralized by the students themselves in their future learning. 
The ultimate goal of learning advocated by the skill acquisition theory was to make the proceduralized knowledge automatically retrieved whenever the students needed it. Thus, the skill acquisition theory is useful in analyzing the function of oral CF because of these three stages of learning development mentioned above.

\section{Methods}

\section{A. Participants}

Five students were enrolled in this ESL Listening and Speaking class. They were two male and three female students with the ages ranging from 18-25. Among these five students, two were from Saudi Arabia, two from Korea, and one from Albania. All of them were in the U.S. for under six months. The female instructor in this class has been teaching ESL for about six years. She is a native English speaker.

\section{B. Setting}

The university in which the present study was conducted is located in a Midwestern US state. It offers 277 degree and certificate programs, including bachelor's degrees, professional certificates, masters degrees and doctoral degrees. Currently, more than 19,000 students are enrolled in majors such as Arts and Sciences, Business Administration, Education and Human Services, Engineering and Computer Science, Health Sciences, Nursing, and Medicine.

The ESL program at the university was established in 1999. It has trained students from more than 50 countries. This program consists of three required courses: speaking/listening, reading, and writing. Each of the three courses has eight levels with level one being the lowest and level eight the highest. Basically, these courses are for non-native speakers whose English proficiency needs to be improved before they receive further undergraduate or graduate education.

The course I observed was Speaking/Listening, which provides students with suitable training to support them with necessary skills in an English-speaking academic environment. Among the eight levels of this course, the level one and two provide basic practice in English conversation. Level three is mainly for the practice of conversational skills. Students are introduced to American culture and customs in level four. In level five, students learn more about listening and speaking for academics. Level six provides students with opportunities to practice academic conversations with native speakers. More importance to specific academic skills in communication is attached at level seven and eight. To move from one level to the next, students are first required to get a certain grade at the original level. From the consecutive order of the eight levels, we can see that students are gradually exposed to the real practices of the academic communications environments that they will be facing after finishing the courses. The Listening and Speaking class I observe is level seven, at which students receive practice in both academic speaking and listening and English language proficiency tests. Compared with other lower levels, students at level seven tend to have relatively more interactions with instructors or peers, which can produce more useful data for the analysis of oral CF frequency.

\section{Methodology}

The data in this study were collected by means of classroom observations. First of all, the observer's field notes were used as a supplementary resource for the investigation of the use of frequency of oral CF. In the field notes, the observer wrote down as much information as possible using brief forms so that he could keep pace with the movement of the class. After each session of the classroom observations, the field notes were modified through the observer's retrospection, and observer comments were added as well if needed. Second, the observer videotaped three sessions of the Listening and Speaking class. Transcription and coding of data followed each of the three sessions.

\section{Procedures}

After establishing the research purpose, the researcher made a contact with the head of the ESL faculty at the university, and obtained permission to observe level seven of Listening and Speaking classes. Subsequently, the researcher went into the class to observe after obtaining the university's Institutional Review Board's (IRB) clearance.

To collect the classroom observation data about oral CF classification and frequency, the researcher observed an ESL Listening and Speaking class for seven hours over two weeks. The instruction time for each class was one and a half hours, and there were five students in the class. The classes were videotaped and transcribed. Because of the audio problems with the settings of the camera in the first observation, the researcher did not derive any useful data from it. Therefore, as a matter of fact, the researcher observed the class four times, but only transcribed three sessions.

\section{E. Data Analysis}

After each session of the observations, the researchers transcribed and coded the videotaped data according to a code-book adapted from Lee's (2013) classification of CF types. In Lee's (2013) study, the author classified CF into six types, which were explicit correction, recast, clarification request, meta-linguistic feedback, elicitation, and repetition. However, based on the data in our study, the researcher derived 13 oral CF types:explicit correction, recast, clarification request, repetition of questions, repetition of students' errors, elicitation with questions, support with example, elicitation with encouragements, elicitation for correction, explanation about language rules, explanation about meanings, direct denial, and explicit agreement.

Different from Lyster and Ranta's (1997) and Sheen's (2004) studies, the error treatment sequences in the present 
study were operationalized as a question posed by the teacher, the students' responses, then the feedback provided by the teacher. For example,

T: What is the meaning of "call in"?

S: Present?

T: Think about this, "I don't feel good, I am gonna call in to my job. I am gonna call in sick to work today." (30-32)

To establish inter-rater reliability about oral CF classification and frequency, the researcher invited three inter-raters to code $10 \%$ of the data independently, among whom two were Ph.D. candidates in reading education who are also EFL teachers and speakers of English as a second language themselves, and the other one was a faculty member. After the three inter-raters finished their coding, they discussed the divergences in the coding, and agreed on how these divergences should be coded, either by adding new codes, or by combining some of the existing ones together. Subsequently, the faculty member independently coded these data. The inter-rater reliability correlation was 0.95 .

\section{Results}

The data contained 154 turns of oral CF provided by the instructor. These turns can be classified into 13 types of oral $\mathrm{CF}$, of which the frequency and the rate are indicated in Table 1.

Of all the oral CF types, the instructor in the university-level ESL Listening and Speaking class utilized elicitation with questions most frequently, with a rate of $17.5 \%$. The frequencies of utilizing other types of oral CF were as follows: explanation about meanings (13.6\%), explanation about language rules (12.3\%), support with examples (9.1\%), repetition of students' errors $(9.1 \%)$, direct denial $(7.1 \%)$, clarification request $(7.1 \%)$, repetition of questions $(5.2 \%)$, explicit correction (5.2\%), elicitation for correction (5.2\%), elicitation with encouragements $(3.9 \%)$, recast $(3.2 \%)$, explicit agreement $(1.2 \%)$.

Generally, the results of the present study indicated that the instructor utilized the elicitation with questions feedback type more than others. In other words, the instructor thought that prompting the students to find out answers by posing questions to which they needed to respond played a significant role in this ESL Listening and Speaking class. In addition, the instructor frequently explained language rules to the students in certain contexts in order to provide them with corrective feedback. However, we found that the feedback type of recast, which was utilized most frequently by ESL instructors in the literature, was only utilized a few times in the present study. Therefore, we may assume that the instructor in our study thought that it was not useful to "reformulate all or part of the incorrect word or phrase, to show the correct form without explicitly identifying the error" (Lee, 2013, p. 218).

TABLE 1

FREQUENCY OF FEEDBACK TYPES

\begin{tabular}{|l|l|l|}
\hline Feedback types & Frequency & Rate \\
\hline Explicit corrections & 8 & $5.2 \%$ \\
Recast & 5 & $3.2 \%$ \\
Clarification requests & 11 & $7.1 \%$ \\
Repetition of questions & 8 & $5.2 \%$ \\
Repetition of students' errors & 14 & $9.1 \%$ \\
Elicitation with questions & 27 & $17.5 \%$ \\
Support with examples & 14 & $9.1 \%$ \\
Elicitation with encouragements & 6 & $3.9 \%$ \\
Explanation about language rules & 19 & $12.3 \%$ \\
Explanation about meanings & 21 & $13.6 \%$ \\
Elicitation for correction & 8 & $5.2 \%$ \\
Direct denial & 11 & $7.1 \%$ \\
Explicit agreement & 2 & $1.2 \%$ \\
\hline Total & 154 & $100 \%$ \\
\hline
\end{tabular}

\section{DISCUSSION}

The present study explored the question what types of oral CF the instructor provided in an university-level ESL Listening and Speaking class. The results indicated that the instructor utilized 13 types of oral CF in the class, and the frequency of utilizing them were (from high to low frequency): elicitation with questions, explanation about meanings, explanation about language rules, support with examples, repetition of students' errors, direct denial, clarification request, repetition of questions, explicit correction, elicitation for correction, elicitation with encouragements, recast, correct. Among them, there three groups of seven types of oral CF that have the same frequency: support with examples and repetition of students' errors; direct denial and clarification request; repetition of questions, explicit correction and elicitation for correction.

The results of the present study were distinguished from the former studies in both the frequencies and the classification of oral CF types. First, in terms of CF frequencies, the present study found that elicitation with questions was most frequently utilized by the instructor. In other words, the instructor frequently prompted the students to find out answers themselves in providing feedback instead of presenting them with the answers directly. For example:

T: Please do not bring up all information about my past. What does "bring up" mean here? 
S: It is something...

$\mathrm{T}$ : Something from where? (11-13)

In this example, the student didn't provide a correct answer to the instructor's question. The instructor, instead of presenting the meaning of "bring up" directly, tried to encourage the student to find out the answer herself.

However, in some other studies on oral CF associated with ESL classes, the results showed that recast was most frequently utilized by the instructors. For example, in Ellis et al.'s (2001) study on oral CF of a New Zealand ESL class, the results showed that for the 189 turns of oral CF, the instructors utilized recast in 129 turns, occupying $68.3 \%$ among the six types of oral CF. Also, in Panova and Lyster's (2002) study, there were 412 oral CF moves provided by the instructors. Among them, 226 moves were delivered to the students by the type of recast, occupying 55\% of all seven types of oral CF in that study. However, in the present study, recast was only utilized by the instructor for five oral CF moves among the 154 in total, or $5.2 \%$ overall. For example:

T: Please do not bring up all information about my past. What do we mean here?

S: ... in our mind?

T: Come to ... mind. (14-16)

In this example, the instructor reformulated the student's incorrect phrase by providing the correct form. Moreover, the feedback type of elicitation with questions, which was utilized most frequently in the present study, was not utilized frequently in either Ellis et al.'s (2001) or Panova and Lyster's (2002) studies, with only 13 turns in the former and 15 in the latter. In addition, the former studies classified elicitation as just one type of feedback. However, in the present study, we found that elicitation could be sub-classified as elicitation for correction, elicitation with questions, with encouragements, and support with examples. As a matter of fact, the classification of oral CF types in the present study was more detailed than the frequently used one in the oral CF literature, which was originated from Lyster and Ranta's (1997) study.

Second, in terms of the classification of oral CF, the present study was distinguished from the former related studies. Most former studies on oral CF classified feedback into six types, which were explicit corrections, recasts, clarification requests, meta-linguistic feedback, elicitation, repetition (e.g., Lyster and Ranta, 1997; Sheen, 2004; Lee, 2013). Initially, we adopted this classification to analyze our transcriptions, conducting a priori coding. However, we found that this classification didn't work well with our data since some of them could not be coded if we utilized that classification. Therefore, a classification of 13 types of oral CF was developed based on our transcriptions. Among these 13 types of oral CF, some remained the same as the former studies, such as explicit correction, recasts, and clarification requests. Some were expanded from those in the former studies, such as repetition of questions, repetition of students' errors (originally classified as repetition); elicitation with questions, with encouragements, elicitation for correction, and support with examples (originally classified as elicitation). Some were newly created based on the present study, such as explanation about language rules, about meanings; direct denial; explicit agreement.

\section{CONCLUSION}

\section{A. Limitations of the Study}

There were several limitations in the present study. First, the total observation time was not quite long enough. Future studies can extend the observation time, which may lead to more solid results about the classification and frequency of oral CF. Second, the present study didn't take into consideration the students' uptake status after receiving oral CF from the teacher. It is not uncommon that students cannot utilize teacher's feedback correctly and efficiently. Thus, the various types of students' uptake status should be investigated in future studies, which will contribute more practical evidence to oral CF studies. In other words, future studies can explore the effectiveness of these oral CF types. Third, the views of the students and the teacher about these 13 types of oral CF were not explored in the present study. Future studies, for example, can utilize questionnaire or interviews to investigate students' and teachers' preferences to the different types of oral CF. For example, if teachers utilized elicitation with question type more frequently than the other feedback types, and students, however, prefer recast feedback type, then the conflict between them need to be addressed to help improve students' oral proficiency. Thus, the data derived from class observations should be triangulated to lead to more significant results in terms of how to use feedback effectively in ESL classes.

\section{B. Conclusions}

The present paper investigated what types of oral CF the instructor provided for the students in an university-level ESL Listening and Speaking class. The results indicated that there were 13 different types of oral CF provided by the instructor, which was a more detailed classification compared with the former related studies. In addition, the present study also was distinguished from the former related studies in terms of frequency of utilizing these types of oral CF, indicating that the instructor in this study utilized elicitation with questions most frequently when providing oral CF, which can be regarded as a sub-classification of elicitation. Also, recast, which was utilized most frequently as a type of oral CF in most related studies, was utilized just a few times. The results of the present study can contribute to the related literature by presenting a detailed classification of oral $\mathrm{CF}$, and the different frequencies of utilizing oral CF, with which can help ESL instructors in providing oral CF in class and in conducting research about how to provide effective oral CF. 


\section{REFERENCES}

[1] Aljaafreh, A. \& Lantolf, J. (1994). Negative feedback as regulation and second language learning in the zone of proximal development. The Modern Language Journal, 78(4), 465-483.

[2] Ellis, R., Basturkmen, H. \& Loewen, S. (2001). Learner uptake in communicative ESL lessons. Language Learning, 51(2), 281-318.

[3] Lee, E. J. (2013). Corrective feedback preferences and learner repair among advanced ESL students. System, 41, $217-230$.

[4] Li, S. (2010). The effectiveness of corrective feedback in SLA: A meta-analysis. Language Learning, 60(2), 309-365.

[5] Long, M. H. (1983). Linguistic and conversational adjustments to non-native speakers. Studies in Second Language Acquisition, $5,177-193$

[6] Long, M. H. (1996). The role of the linguistic environment in second language acquisition. In (Series Ed.) \& W. C. Ritchie, \& T. K. Bhatia (Vol. Eds.), Second language acquisition: Vol. 2. Handbook of language acquisition (pp. 413-468). New York: Academic.

[7] Lyster, R. \& Ranta, L. (1997). Corrective feedback and learner uptake: Negotiation of form in communicative classrooms. Studies in Second Language Acquisition, 19(1), 37-66.

[8] Lyster, R., Saito, K., \& Sato, M. (2013). Oral corrective feedback in second language classrooms. Language Teaching, 46, 1-40. http://doi:10.1017/S0261444812000365.

[9] Panova, I. \& Lyster, R. (2002). Patterns of corrective feedback and uptake in an adult ESL classroom. TESOL Quarterly, 36(4), 573-595.

[10] Pawlak, M. (2014). Error correction in the foreign language classroom reconsidering the issues. Berlin: Springer.

[11] Polio, C. (2013). The relevance of second language acquisition theory to the written error correction debate. Journal of Second Language Writing, 21, 375-389. http://dx.doi.org/10.1016/j.jslw.2012.09.004.

[12] Sarandi, H. (2016). Oral corrective feedback: A question of classification and application. TESOL Quarterly, 50(1), $235-246$. http://doi: 10.1002/tesq.285.

[13] Sheen, Y. (2004). Corrective feedback and learner uptake in communicative classrooms across instructional settings. Language Teaching Research, 8(3), 263-300.

[14] Tsang, W. K. (2004). Feedback and uptake in teacher-student interaction: an analysis of 18 English lessons in Hong Kong secondary classrooms. RELC Journal, 35, 187-209.

[15] White, L. (1991). Adverb placement in second language acquisition: some effects of positive and negative evidence in the classroom. Second Language Research, 7, 133-161.

[16] Yang, Y. (2009). Feedback and uptake in Chinese EFL classrooms: In search of instructional variables. The Journal of ASIA TEFL, 6(1), 1-22.

Ning Fan was born in Guizhou Province, China in 1980. He finished his MA in Foreign and Applied Linguistics in Guizhou University, China in 2013. He is currently a doctoral student in the School of Education and Human Services, Oakland University, Michigan, US. His research field includes second language writing and language education. 